Ciência e Natura, Santa Maria, v. 37 n. 4 set-dez 2015, p. 284-297

Revista do Centro de Ciências Naturais e Exatas - UFSM

ISSN impressa: 0100-8307 ISSN on-line: 2179-460X

\title{
Influência do El Niño e La Niña no número de dias de precipitação pluviométrica no Estado do Mato Grosso
}

\author{
Influence of El Niño and La Niña in the number of days of rainfall in the state of Mato Grosso.
}

\section{Nayhara de Lima Oliveira ${ }^{1}$, Francisco Fernando Noronha Marcuzzo ${ }^{2}$, Rosana Gonçalves Barros ${ }^{1}$}

${ }^{1}$ IFG - Instituto Federal de Educação, Ciência e Tecnologia de Goiás.

${ }^{2}$ CPRM/SGB - Companhia de Pesquisa de Recursos Minerais / Serviço Geológico do Brasil.

\begin{abstract}
Resumo
A análise da intensidade dos fenômenos El Niño e La Niña e sua influência na distribuição temporal da precipitação se tornam importante, uma vez que possibilita detectar tendências ou alterações no ciclo hidrológico de regiões visando melhorar o manejo de águas pluviais oriundas de eventos climáticos. O presente trabalho teve como objetivo correlacionar a variação do NDC (Número de Dias de Chuva) no Estado do Mato Grosso com a intensidade do Índice Oceânico Niño(a) (ION). Utilizaram-se dados de 76 estações pluviométricas com 30 anos de dados e 44 estações com dados variando de 20 a 29 anos, sendo que toda série histórica está entre os anos de 1977 a 2006. Os dados mensais de intensidade dos fenômenos climáticos El Niño e La Niña foram obtidos do Serviço Climatológico Nacional dos Estados Unidos (NOAA - National Weather Service), os quais foram relacionados com os dados mensais do NDC a fim de descrever o caminhamento da evolução do mesmo sob a influência do ION. No período de 1977 a 2006 o ION mensal médio variou entre $-1,1^{\circ} \mathrm{C}$ e $1,3^{\circ} \mathrm{C}$, variações consideradas moderadas, com algumas variações consideradas fortes nos anos de $1982\left(2,3^{\circ} \mathrm{C}\right), 1983\left(2,3^{\circ} \mathrm{C}\right), 1988\left(-1,9^{\circ} \mathrm{C}\right), 1991\left(1,6^{\circ} \mathrm{C}\right)$, $1992\left(1,8^{\circ} \mathrm{C}\right), 1997\left(2,5^{\circ} \mathrm{C}\right), 1998\left(2,3^{\circ} \mathrm{C}\right), 1999 / 2000\left(-1,6^{\circ} \mathrm{C}\right)$ e $2002\left(1,5^{\circ} \mathrm{C}\right)$. No período em estudo houve mais variações positivas de temperatura do que negativas das águas do Oceano Pacífico, caracterizando uma maior frequência do fenômeno El Niño. A maior parte dos NDC extremos de cada mês da série histórica, ou seja, aqueles valores de NDC que estavam acima ou abaixo da média não estavam associados ao fenômeno ION. Assim, conclui-se que as variações da Temperatura da Superfície do Mar (TSM) do oceano Pacífico não causam efeitos significativos ou evidentes no NDC do Estado de Mato Grosso.
\end{abstract}

Palavras-chave: Temperatura do Oceano Pacífico, ENOS, Número de Dias de Chuva.

\begin{abstract}
The analysis of the intensity of El Niño and La Niña and its influence on the temporal distribution of rainfall becomes important, since it allows to detect trends or changes in the hydrological cycle of regions to improve the management of stormwater arising from climate events. This study aimed to correlate the variation of the NDC (Number of Days of Rain) in the state of Mato Grosso to the intensity Oceanic Niño Index (a) (ION). We used data from 76 rainfall stations with 30 years of data and 44 stations with data ranging from 20 to 29 years, and throughout this series between the years 1977 to 2006. Monthly data on the intensity of weather phenomena El Niño and La Niña were obtained from the National Service Climatologic U.S. (NOAA - National Weather Service), which were related to monthly data from NDC to describe the pathway of evolution of the same under the influence of ION. In the period 1977 to 2006 the average monthly ION ranged between $-1.1^{\circ} \mathrm{C}$ and $1.3^{\circ} \mathrm{C}$, variations considered moderate, with some variations considered strong in $1982\left(2.3^{\circ} \mathrm{C}\right), 1983$ $\left(2,3^{\circ} \mathrm{C}\right) .1988\left(-1.9^{\circ} \mathrm{C}\right), 1991\left(1.6^{\circ} \mathrm{C}\right), 1992\left(1.8^{\circ} \mathrm{C}\right), 1997\left(2.5^{\circ} \mathrm{C}\right), 1998\left(2.3^{\circ} \mathrm{C}\right)$ 1999/2000 $\left(-1.6^{\circ} \mathrm{C}\right)$ and $2002\left(1.5^{\circ} \mathrm{C}\right)$. During the study period there were more positive changes than negative temperature of the waters of the Pacific Ocean, featuring a higher frequency of El Niño. The majority of NDC ends of each month the series, ie those values that were above the NDC below the mean were not associated with the phenomenon ION. Thus, it is concluded that the variations of sea surface temperature (SST) of the Pacific Ocean cause no significant effects evident in the NDC or the State of Mato Grosso.
\end{abstract}

Keywords: Temperature of the Pacific Ocean, ENOS, Number of Days of Rain. 


\section{INTRODUÇÃO}

O Mato Grosso concentra boa parte da economia nos agronegócios, que dependem de toda uma cadeia produtiva embasada na agricultura e pecuária. $\mathrm{O}$ excesso ou a falta de chuva pode ser favorável ou prejudicial ao desenvolvimento da economia, dessa forma, a análise dos fatores que interferem na precipitação pluviométrica do Estado é de extrema importância. Dentro desse contexto a relação vegetação-atmosfera-vida está comprovada e sujeita a estudos que melhor caracterize os fenômenos ENOS e seus efeitos sob o ciclo hidrológico e consequentemente sob os diversos setores da sociedade como economia, meio ambiente e qualidade de vida.

As análises das variações de temperatura das águas no Oceano Pacífico bem como sua influência sob o ciclo hidrológico são de grande importância para estudos de comportamento pluviométrico que é uma das essências para a manutenção da vida e da boa condutividade das atividades humanas de abastecimento de água, de infraestrutura e produtivas em geral, que interagem com o meio natural. Devido ao pequeno espaçamento temporal de dados pluviométricos, notadamente escassos no Estado do Mato Grosso, há uma carência muito acentuada de estudos que mostrem a correlação de chuvas neste Estado com fenômenos climáticos de influência mundial, como o El Niño e a La Niña.
El Niño Oscilação Sul (ENOS) é um fenômeno de interação oceanoatmosfera, associado às alterações dos padrões normais da TSM (temperatura da superfície do mar) e dos ventos alísios na região do Pacífico Equatorial, entre a Costa Peruana e a Austrália (MORAES et al., 2007), em que, na fase negativa (La Niña), as chuvas são geralmente abaixo da normal climatológica e, na fase positiva, (El Niño) são geralmente acima da normal (GRIMM et al., 1998, 2000; BERLATO \& FONTANA, 2003).

Certas características do ENOS levaram a pontos de vista conflitantes, principalmente em relação à ocorrência irregular das fases quentes e frias com um ciclo de duração média de 4 anos, mas incluindo ciclos irregulares e de intensidade variável, podendo durar de 2 a 7 anos. Tais variações tornam difícil prever a ocorrência do ciclo. A previsibilidade do fenômeno ENOS depende de previsões probabilísticas (PHILANDER E FEDOROV, 2003).

Ribeiro \& Lunardi (1997) destaca a importância da caracterização pluviométrica de um local para o planejamento de diversas atividades essenciais a sociedade como a agricultura, sendo imprescindível também no dimensionamento de reservatórios de água, na elaboração de projetos de proteção e conservação de solos e em atividades de lazer e esportivas. Contudo a previsão de dias com chuva fica comprometida devido à anormalidade dos fenômenos ENOS.

Entre as consequências do ENOS podem ser destacados: o aumento das 
precipitações no sul da América do Sul, atingindo proporções catastróficas como em 1983, e a seca nas regiões Norte e Nordeste do Brasil para o mesmo período (BRASIL, 1997).

Em um estudo sobre a precipitação máxima diária no Mato Grosso do Sul, Marcuzzo e Oliveira (2012) relatam que as mesmas são mais intensificadas durantes episódios de El Niño, levando a conclusão de que o fenômeno El Niño causa mais impactos do que o fenômeno La Niña nas precipitações do estado.

A precipitação pluvial medida em estações meteorológicas nem sempre é um bom parâmetro para avaliar se a disponibilidade hídrica em determinado período é suficiente para o atendimento das necessidades das culturas agrícolas. Os totais de precipitação pluvial correspondem a todo o período considerado, não sendo levado em conta se foram bem distribuídos ao longo do período ou se ocorreram em um único dia (FISCHER et al., 2008).

Diante da escassez de estudos e pesquisas sobre a influência do El Niño e La Niña na região Centro-Oeste do Brasil, bem como suas consequências no âmbito da distribuição temporal das chuvas; o objetivo desse estudo é analisar o impacto desses fenômenos no Número de Dias de Chuva no Estado do Mato Grosso a partir do estudo da sua dispersão, correlação, medidas de tendência central e de variação dos valores.

\section{MATERIAL E MÉTODOS}

O Estado de Mato Grosso (Figura 1) está localizado na região Centro-Oeste do Brasil. O Estado de Mato Grosso possui uma área total de $903.329,700 \mathrm{~km}^{2}$ e perímetro de $5.815,15$ $\mathrm{km}$ e possui 141 municípios sendo que o maior território municipal do Estado pertence ao município de Aripuanã (área de 65.639,97 km² e perímetro de $1.288,36 \mathrm{~km}$ ) e o menor, o município de São Pedro da Cipa (área de 343,89 km² e perímetro de 108,82 km). Segundo dados do IBGE (2010), toda a população residente nos municípios do Estado de Mato Grosso somam 3.035.122 pessoas, sendo que a maior densidade populacional pertence ao município de Cuiabá, com 163,88 habitantes. $\mathrm{km}^{-2}$.

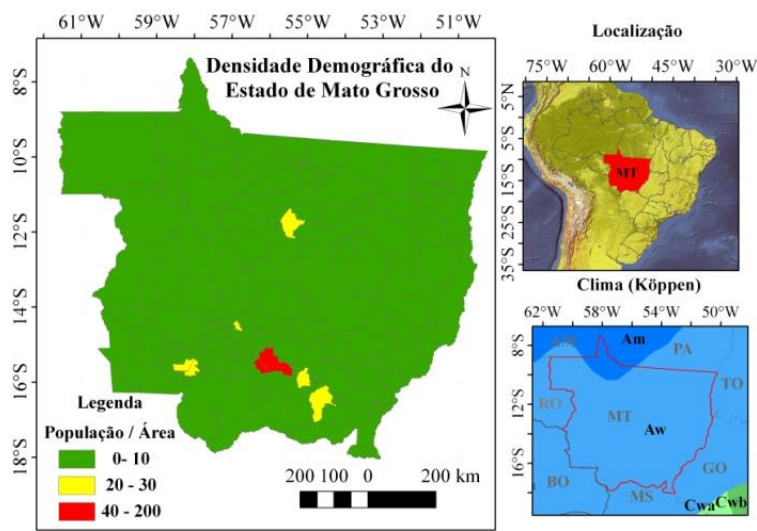

Figura 1 - Densidade de habitantes por quilômetro quadrado, clima e localização do Estado de Mato Grosso.

O clima do Estado de Mato Grosso, segundo a classificação de Köppen, em grande parte é o Tropical $(\mathrm{Aw})$, com estação seca no inverno (Figura 1), ficando uma pequena parte ao norte do Estado com o clima Tropical Monçônico (Am), chuvas excessivas durante o ano, porém com inverno seco (PEEL et al., 2007). 
No presente trabalho foram utilizados dados do projeto SRTM (Shuttle Radar Topographic Mission) do qual foram obtidos imagens com resolução de 90 metros as quais foram agrupadas em um programa GIS (Geographic Information System) e em seguida o MDE (Modelo Digital de Elevação) foi delimitado o que permitiu analisar a hipsometria do Estado de Mato Grosso. O Estado de Mato Grosso está inserido nos biomas Amazônia, Cerrado e Pantanal (Figura 2).

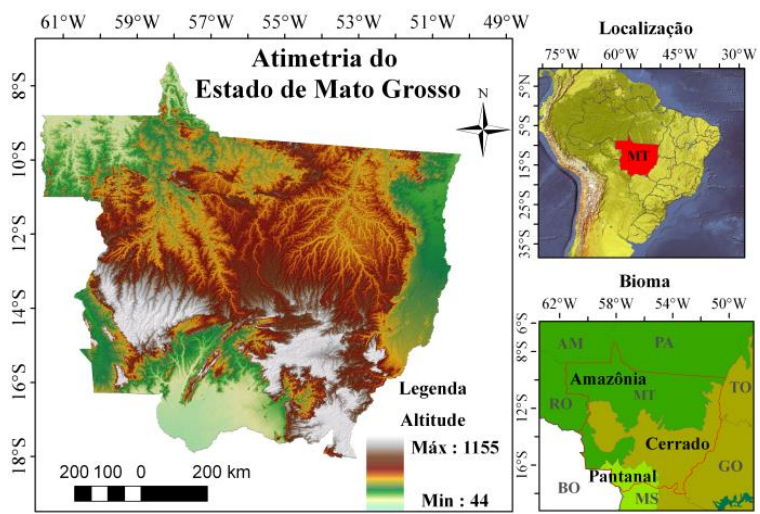

Figura 2 - Relevo, altimetria, localização e bioma do Estado do Mato Grosso.

Segundo os dados extraídos por SRTM, a amplitude altimétrica do Estado de Mato Grosso varia de 44 a 1.155 metros, sendo que as regiões sudoeste e sudeste do Estado apresentam as maiores altitudes (Figura 2).

O uso do solo no Estado de Mato Grosso se distribui entre a pecuária, agricultura e a agropecuária, porém a maior parte do solo é ocupada por vegetação remanescente (Figura 3).

Utilizou-se neste estudo 120 estações pluviométricas (Figura 3), sendo 76 estações pluviométricas com 30 anos de dados e 44 estações com dados variando de 20 a 29 anos cujos dados mensais do Número de Dias de Chuva utilizados neste estudo foram obtidos da Rede Hidrometeorológica Nacional da Agência Nacional de Águas (ANA) e da CPRM/SGB (Companhia de Pesquisa de Recursos Minerais / Serviço Geológico do Brasil). Estes dados diários de NDC correspondem a uma série histórica de 1977 a 2006 e foram compilados, consistidos, organizados e tratados estatisticamente, com informação diária, mensal, anual e sazonal.

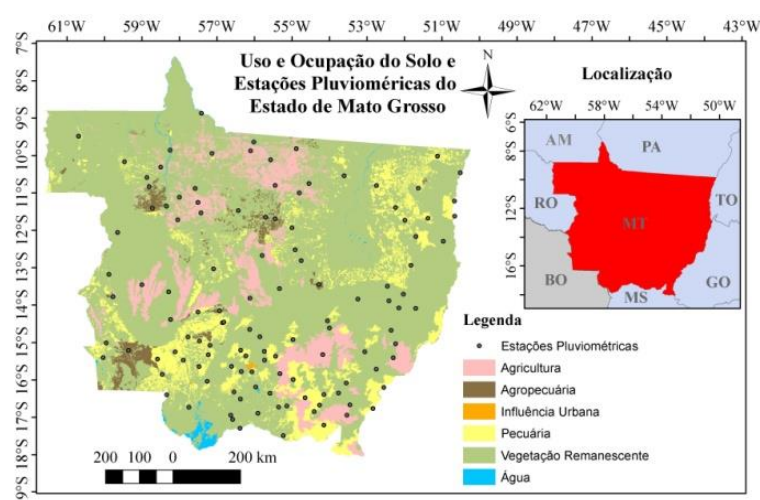

Figura 3 - Uso e ocupação do solo, estações pluviométricas e localização do Estado do Mato Grosso.

O ION (Índice Oceânico Niño (a)) é um índice que identifica as anomalias da superfície do Oceano Pacífico através de uma média móvel de três meses (Figura 4). Quando o ION for maior que $+0,5^{\circ} \mathrm{C}$ por no mínimo cinco meses consecutivos o período é caracterizado como El Niño, e quando o índice for menor que $-0,5^{\circ} \mathrm{C}$ por no mínimo cinco meses consecutivos o período é caracterizado como La Niña, assim variações de até 0,5 graus na temperatura das águas do Oceano Pacífico são consideradas normais. No 
Quadro 1 observa-se a intensidade do fenômeno ENOS que foi classificada em classes fraca, moderada e forte utilizando-se a média do ION.

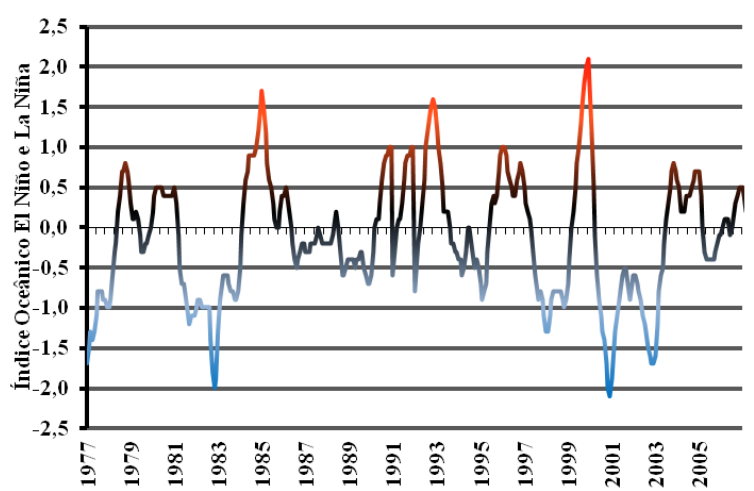

Figura 4 - Índice oceânico El Niño e La Niña para o período histórico estudado.

Quadro 1 - Critérios para classificar a intensidade do fenômeno ENOS usado no estudo.

\begin{tabular}{|l|c|l|}
\hline Evento & Índice Oceânico Niño & Intensidade \\
\hline \multirow{3}{*}{ El Niño } & 0,5 a 0,9 & Fraca \\
& 1,0 a 1,4 & Moderada \\
& $\geq 1,5$ & Forte \\
\hline \multirow{3}{*}{ La Niña } & $-0,5 \mathrm{a}-0,9$ & Fraca \\
& $-1,0 \mathrm{a}-1,4$ & Moderada \\
& $\leq-1,5$ & Forte \\
\hline
\end{tabular}

Fonte: Golden Gate Weather Services (2008).

Os dados de intensidade dos fenômenos climáticos El Niño e La Niña (Figura 4) foram obtidos do Serviço Climatológico Nacional dos Estados Unidos (NOAA - National Weather Service).

\section{Regressão linear e polinomial}

São métodos para se estimar a condicional de uma variável $Y$, dados os valores de algumas outras variáveis $X$.
A regressão, em geral, trata da questão de se estimar um valor condicional esperado. Em muitas situações, uma relação linear pode ser válida para sumarizar a associação entre as variáveis $Y$ e $X$. Já a regressão polinomial tende a descrever o caminhamento da evolução da variável dependente $Y$ conforme as modificações da variável $X$. A regressão linear $\mathrm{e}$ polinomial é, respectivamente, descrita como:

$\mathrm{Y}=\beta_{0}+\beta_{1} \mathrm{X}$

$Y=\beta_{6} X^{6}+\beta_{5} X^{5}+\cdots+\beta_{1} X+\beta_{0}$

em que, $Y$ é a variável linear dependente; $\beta_{6}, \beta_{5}, \ldots, \beta_{1}$, e $\beta_{0}$ são os coeficientes da regressão; $X$ é a variável independente.

\section{Verificação estatística descritiva}

Através da estatística descritiva, podemos ter características essenciais para a formação de histograma de frequências relativas de uma amostra de dados hidrológicos (NAGHETTINI \& PINTO, 2007). Para este estudo foram calculadas as seguintes medidas de tendência central e de dispersão.

\section{Verificação estatística descritiva}

Através da estatística descritiva, podemos ter características essenciais para a formação de histograma de frequências relativas de uma amostra de dados hidrológicos (NAGHETTINI \& PINTO, 2007). Para este estudo foram 
calculadas as seguintes medidas de tendência central e de dispersão.

\section{-Medidas de tendências centrais}

A média é a medida de posição mais usada e tem um significado teórico importante na estimativa de amostras. É calculada pela seguinte fórmula:

$\mathrm{X}=\frac{\mathrm{x}_{10 m, \mathrm{X}_{\mathrm{n}}}}{\mathrm{N}}=\frac{1}{\mathrm{~N}} \sum_{\mathrm{i}=1}^{\mathrm{N}} \mathrm{X}_{1}$

em que, $X$ - é a média; $N$ - tamanho da amostra; $X_{1}$ até $X_{n}$ - somatórios da amostra.

A mediana é outra medida de posição mais resistente do que a média, por ser imune á eventual presença de valores extremos discordantes na amostra. É calculada pela equação:

$\mathrm{X}_{\text {med }}=\frac{\mathrm{x}_{\left(\frac{N}{2}\right)}+\mathrm{x}_{\left(\frac{N}{3}+1\right)}}{2}$

em que, $N$ - tamanho da amostra; $X$ posições das amostras.

\section{- Medidas de dispersão}

O desvio padrão é fortemente influenciado pelos menores e maiores desvios, constituindo-se na medida de dispersão mais frequentemente usada. É calculado pela seguinte expressão:

$$
\mathrm{S}=\sqrt{\frac{1}{\mathrm{~N}-1} \sum_{\mathrm{I}=1}^{\mathrm{N}}\left(\mathrm{X}_{1}-\mathrm{X}\right)^{2}}
$$

em que, $N$ - tamanho da amostra; $X_{i}$ valor de cada amostra; $\bar{X}$ - média.

Utilizando-se as medidas de tendência central e de dispersão podemse verificar analiticamente os parâmetros, e observar se as amostras são diferentes ou semelhantes.

\section{RESULTADOS E DISCUSSÃO}

Nos meses de janeiro (Figura 5) de 1977 a 2006 os fenômenos El Niño e La Niña aconteceram com intensidades consideráveis, contudo não tiveram interferência no NDC. A maior variação de temperatura positiva (El Niño) foi de $2,3^{\circ} \mathrm{C}$ (intensidade forte), nos anos de 1983 e 1998, correspondendo a um NDC de 18 dias e 15 dias respectivamente. A intensidade máxima do fenômeno $\mathrm{La}$ Niña foi de $-1,7^{\circ} \mathrm{C}$ (intensidade forte) no ano de 1989, correspondendo a um NDC de 19 dias. O maior NDC observado foi de 22 dias (1985) e estava sob influência de uma La Niña de intensidade fraca $\left(-0,9^{\circ} \mathrm{C}\right)$. $\mathrm{O}$ menor NDC (11 dias) ocorreu no ano de 1993 e não estava sob influência de nenhum dos fenômenos em estudo.

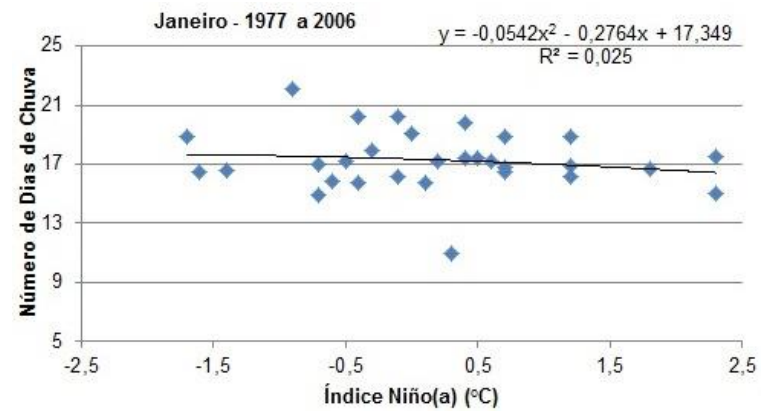

Figura 5 - Dispersão em janeiro do Número de Dias de Chuva em relação ao Índice Niño(a) do período.

No mês de fevereiro (Figura 6) os fenômenos ocorreram em intensidades menores que as do mês de janeiro e com pouca interferência no NDC. O Índice Niño de maior intensidade para o mês de fevereiro foi 
2,0 $0^{\circ} \mathrm{C}$ (intensidade forte) no ano de 1983 ocasionando 13 dias de chuva, já o mais intenso episódio de La Niña foi de $1,5^{\circ} \mathrm{C}$ (intensidade forte), acarretando em 17 dias de chuva no ano de 1989. O mês de fevereiro do ano de 2005 esteve sob influência de um El Niño de fraca intensidade $\left(0,5^{\circ} \mathrm{C}\right)$ e apresentou $\mathrm{o}$ menor NDC da série histórica para este mês (12 dias); contudo o maior NDC (21 dias) aconteceu em 1980 e não coincidiu com a ocorrência de nenhum dos fenômenos.

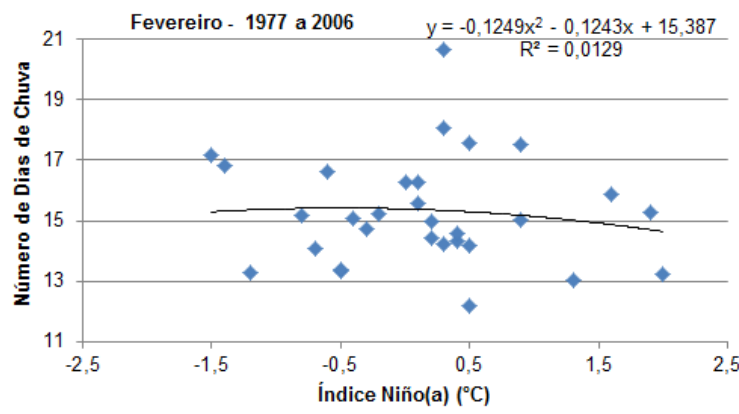

Figura 6 - Dispersão em fevereiro do Número de Dias de Chuva em relação ao Índice Niño(a) do período.

O Índice Niño(a) no mês de março (Figura 7) não sofreu grandes variações de temperatura, nestas condições observou-se uma tendência de crescimento do NDC na ocorrência da La Niña e pouca variação do NDC nos episódios de El Niño. Na maior parte dos meses de março da série histórica a temperatura do Oceano Pacífico se manteve em índices considerados normais. $\mathrm{O}$ mais intenso episódio de La Niña $\left(-1,1^{\circ} \mathrm{C}\right.$, intensidade moderada) ocasionou 17 dias de chuva em 1989. A maior variação positiva de temperatura no Oceano Pacífico para o mês de março foi de $1,5^{\circ} \mathrm{C}$ (intensidade forte) e aconteceu nos anos de 1983 (15 dias de chuva), 1992 (14 dias de chuva) e 1998 (14 dias de chuva). O menor NDC (10 dias, em 1993) e também o maior NDC para este mês (18 dias em 2003) aconteceram sob influência de Índices Niño de $0,6^{\circ} \mathrm{C}$ e $0,5^{\circ} \mathrm{C}$ (intensidade fraca), respectivamente.

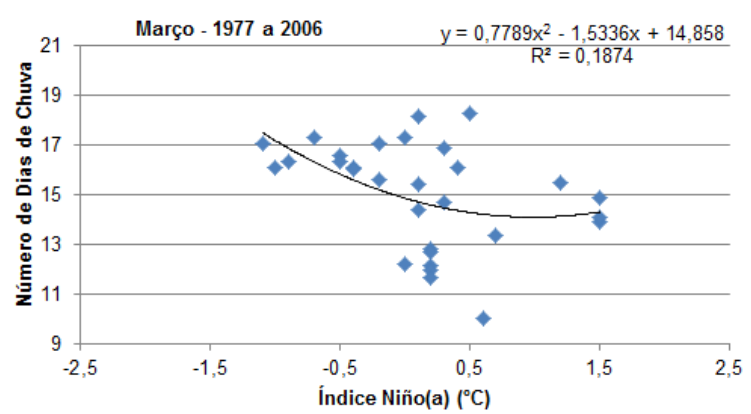

Figura 7 - Dispersão em março do Número de Dias de Chuva em relação ao Índice

Niño(a) do período.

No mês de abril (Figura 8) os Índices Niño(a) não ocorreram em grandes intensidades, além disso, 70\% dos meses de abril da série histórica não estiveram sob influência dos fenômenos em estudo. Nessas condições observouse um pequeno acréscimo do NDC durante os episódios de La Niña e um decréscimo pouco significativo do NDC durante os episódios de El Niño. Em sua fase mais intensa o El Niño $\left(1,4^{\circ} \mathrm{C}\right.$, intensidade moderada) provocou 9 dias de chuva em 1992. O mais intenso episódio de La Niña $\left(-0,8^{\circ} \mathrm{C}\right.$, intensidade fraca) aconteceu nos anos de 1989, 1999 e 2000 e ocasionou 13 dias, 8 dias e 10 dias de chuva, respectivamente. $\mathrm{O}$ maior NDC (15 dias) aconteceu durante um episódio de La Niña de fraca intensidade $\left(-0,7^{\circ} \mathrm{C}\right)$ em 1985 . O menor NDC (6 dias) se deu em 2002 e não 
estava sob influência de nenhum dos fenômenos

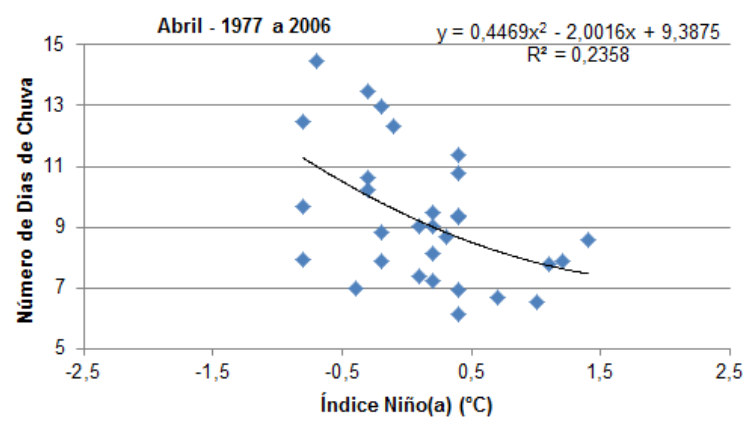

Figura 8 - Dispersão em abril do Número de Dias de Chuva em relação ao Índice Niño(a) do período.

As intensidades dos fenômenos no mês de maio (Figura 9) foram ainda menores se comparadas aos meses anteriores. Constatou-se um decréscimo pouco significativo do NDC na ocorrência tanto da La Niña quanto do El Niño. Choveu 3 dias no mês de maio dos anos de 1992 e 1999, nos quais aconteceu respectivamente, o mais intenso El Niño $\left(1,2^{\circ} \mathrm{C}\right.$, intensidade moderada) e a mais intensa La Niña ($0,8^{\circ} \mathrm{C}$, intensidade fraca). Tanto o maior NDC (7 dias) quanto o menor NDC (1 dia) foram observados durante a não ocorrência dos fenômenos em estudo nos anos de 1977 e 1981, respectivamente.

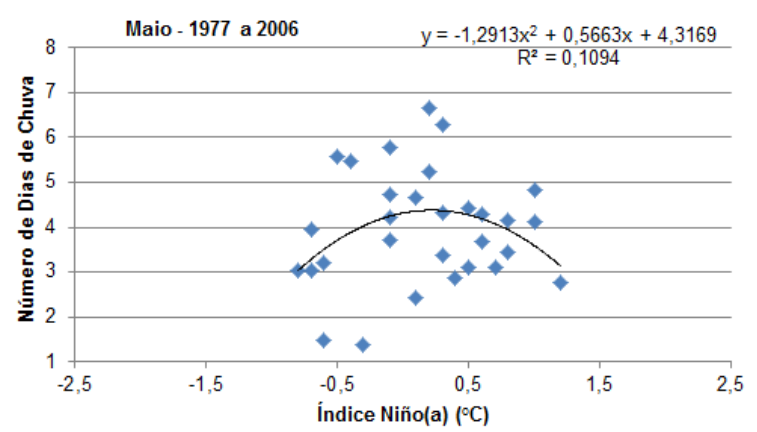

Figura 9 - Dispersão em maio do Número de Dias de Chuva em relação ao Índice Niño(a) do período.

No mês de junho (Figura 10) a variação de temperatura do Oceano Pacífico ficou entre $-1,2^{\circ} \mathrm{C}$ (1 dia de chuva em 1988 ) e $1,3^{\circ} \mathrm{C}$ (4 dias de chuva em 1997). Houve um acréscimo do NDC na ocorrência dos dois fenômenos, mais significativo durante o El Niño. Choveu também 4 dias em 1977, ano no qual não sofreu influência da La Niña ou do El Niño, assim como boa parte dos meses de junho da série histórica. $\mathrm{O}$ mês de junho dos anos $1979\left(-0,1^{\circ} \mathrm{C}\right), 2000$ ($\left.0,5^{\circ} \mathrm{C}\right), 2002\left(0,8^{\circ} \mathrm{C}\right)$ e $2006\left(0,2^{\circ} \mathrm{C}\right)$ não registrou chuva no Estado de Mato Grosso.

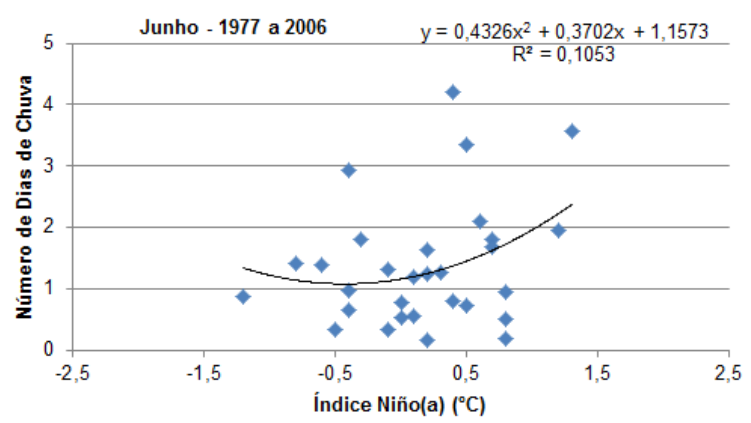

Figura 10 - Dispersão em junho do Número de Dias de Chuva em relação ao Índice Niño(a) do período.

No mês de julho (Figura 11) as relações entre fenômenos ENOS e dias de chuva foram inversamente proporcionais, enquanto o Índice Ninõ(a) aumentava o NDC diminuía. Como o mês de julho se caracteriza pela estiagem no Estado de Mato Grosso, o maior NDC registrado para este mês na série histórica foi 3 dias (1978) e não estava sob influência dos fenômenos em estudo. Não choveu no mês de julho dos 
anos de 1977, 1981, 1984, 1987, 1988, 1991, 1992, 1995, 1996, 1997, 1998, 2003 e 2005, nos quais o Índice Niño(a) variou de $-1,3^{\circ} \mathrm{C}$ a $1,7^{\circ} \mathrm{C}$, incluindo assim os anos de ocorrência da mais intensa $\mathrm{La}$ Niña $\left(-1,3^{\circ} \mathrm{C}\right.$, intensidade moderada) e do mais intenso El Niño $\left(1,7^{\circ} \mathrm{C}\right.$, intensidade forte) para o mês de julho.

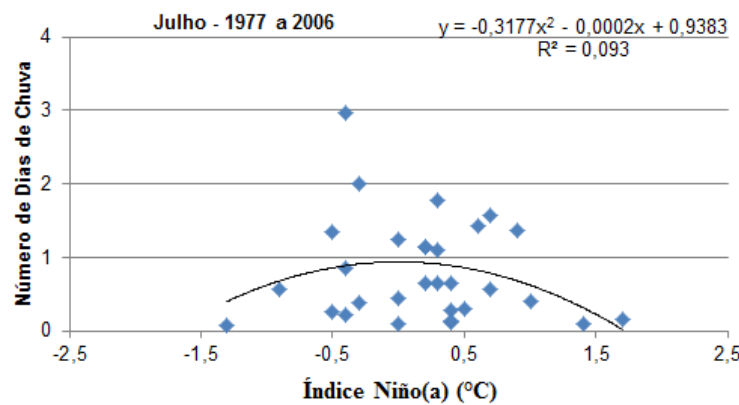

Figura 11 - Dispersão em julho do Número de Dias de Chuva em relação ao Índice Niño(a) do período.

As intensidades do El Niño e da La Niña não diferenciaram muito em relação ao mês anterior, além disso, a tendência de decréscimo do NDC continuou para o mês de agosto (Figura 12). Na ocorrência do El Niño mais intenso $\left(2,0^{\circ} \mathrm{C}\right.$, intensidade forte $)$ registrou-se 1 dia de chuva no ano de 1997. Em $1986\left(0,5^{\circ} \mathrm{C}\right.$, intensidade fraca) aconteceu o máximo NDC para o mês de agosto da série histórica (5 dias). Não foi registrado chuvas nos meses de agosto dos anos de $1978\left(-0,4^{\circ} \mathrm{C}\right), 1983$ $\left(-0,2^{\circ} \mathrm{C}\right), 1988\left(-1,2^{\circ} \mathrm{C}\right.$, La Niña mais intensa), $1991\left(0,9^{\circ} \mathrm{C}\right), 1999\left(-0,9^{\circ} \mathrm{C}\right)$ e $2005\left(0,3^{\circ} \mathrm{C}\right)$.

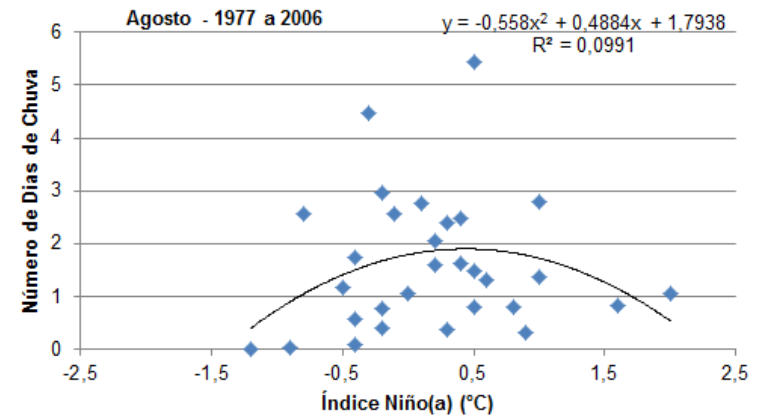

Figura 12 - Dispersão em agosto do Número de Dias de Chuva em relação ao Índice Niño(a) do período.

Apesar do Índice Niño no mês de setembro (Figura 13) chegar a $2,2^{\circ} \mathrm{C}$, não se observou influência do fenômeno no NDC deste mês. Durante a La Niña nota-se um decréscimo pouco significativo do NDC. No ano de 1988 observou-se o menor NDC (2 dias) e também a La Niña mais intensa $\left(-1,3^{\circ} \mathrm{C}\right.$, intensidade moderada) para o mês de setembro. O maior NDC (9 dias) ocorreu em 1982 sob influência de um El Niño de intensidade forte $\left(1,5^{\circ} \mathrm{C}\right)$. Já a variação TSM positiva (El Niño) em sua intensidade máxima $\left(2,2^{\circ} \mathrm{C}\right)$ ocasionou 5 dias de chuva (1997).

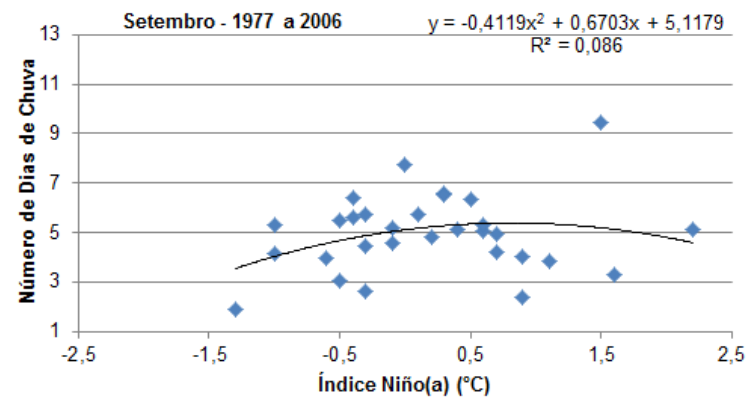

Figura 13 - Dispersão em setembro do Número de Dias de Chuva em relação ao Índice Niño(a) do período.

No mês de outubro (Figura 14) os fenômenos El Niño e La Niña foram relativamente intensos, mas não 
inferiram no NDC, já que a linha de tendência manteve-se praticamente estável durante todo o mês. Valores extremos de La Niña $\left(-1,6^{\circ} \mathrm{C}\right.$, intensidade forte) e El Niño $\left(2,4^{\circ} \mathrm{C}\right.$, intensidade forte) ocasionaram 8 dias de chuva no mês de outubro dos anos de 1988 e 1997, respectivamente. Também choveu 8 dias nos mês de outubro dos anos de $1980\left(-0,1^{\circ} \mathrm{C}\right), 1987\left(1,5^{\circ} \mathrm{C}\right), 1993$ $\left(0,4^{\circ} \mathrm{C}\right), 1995\left(-0,6^{\circ} \mathrm{C}\right), 1999\left(-1,1^{\circ} \mathrm{C}\right), 2000$ $\left(-0,5^{\circ} \mathrm{C}\right)$ e $2005\left(-0,1^{\circ} \mathrm{C}\right)$. O NDC mínimo (6 dias) ocorreu sob temperaturas normais das águas do Oceano Pacifico em 1979. No ano de 1984 sob influência de uma La Niña de intensidade fraca ($0,6^{\circ} \mathrm{C}$ ) se deu o mês de outubro com maior NDC da série histórica, 13 dias.

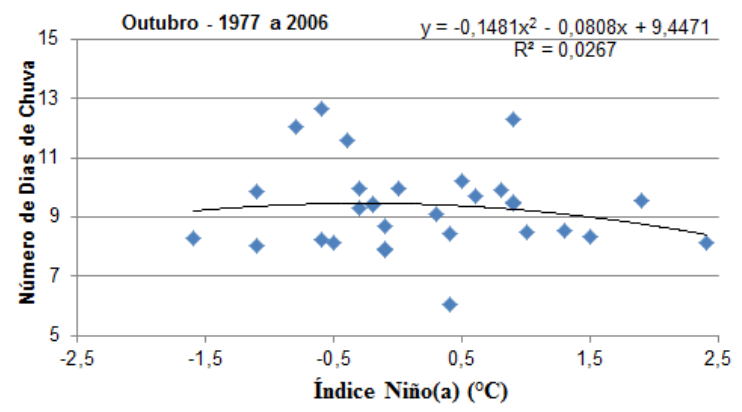

Figura 14 - Dispersão em outubro do Número de Dias de Chuva em relação ao Índice Niño(a) do período.

Índices elevados de El Niño e La Niña foram contatados no mês de novembro (Figura 15), mas apenas a La Niña teve interferência no NDC. Chegando a $-1,9^{\circ} \mathrm{C}$ (intensidade forte) o fenômeno La Niña ocasionou 12 dias de chuva em 1988. O episódio mais intenso de El Niño $\left(2,5^{\circ} \mathrm{C}\right.$, intensidade forte) provocou 11 dias de chuva em 1997. Tanto o menor NDC (9 dias) quanto o maior NDC (15 dias) para o mês de novembro não estavam sob influência dos fenômenos ENOS e se deram nos anos de 1993 e 2001, respectivamente.

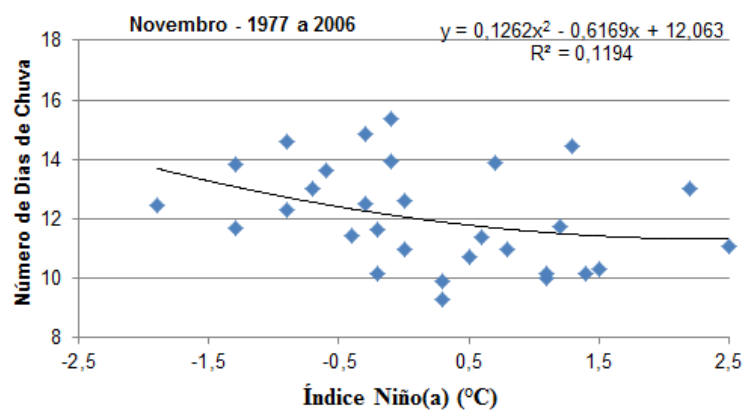

Figura 15 - Dispersão em novembro do Número de Dias de Chuva em relação ao Índice Niño(a) do período.

Seguindo a tendência dos fenômenos, os Índices Niño e Niña atingiram intensidades elevadas no mês de dezembro (Figura 16), se comparados aos meses anteriores, porém pouco influenciou no NDC. Nota-se um acréscimo mínimo do NDC durante a La Niña e um decréscimo também pouco significativo do NDC durante o El Niño. A mais intensa La Niña $\left(-1,9^{\circ} \mathrm{C}\right.$, intensidade forte $)$ provocou 17 dias de chuva em 1988 . O El Niño mais intenso $\left(2,5^{\circ} \mathrm{C}\right.$, intensidade forte) ocasionou 14 dias de chuva em 1997. Tanto o maior NDC (19 dias) quando o menor NDC (13 dias) para este mês não estavam associados a nenhum dos fenômenos e se deram nos anos de 1989 e 1990, respectivamente. 


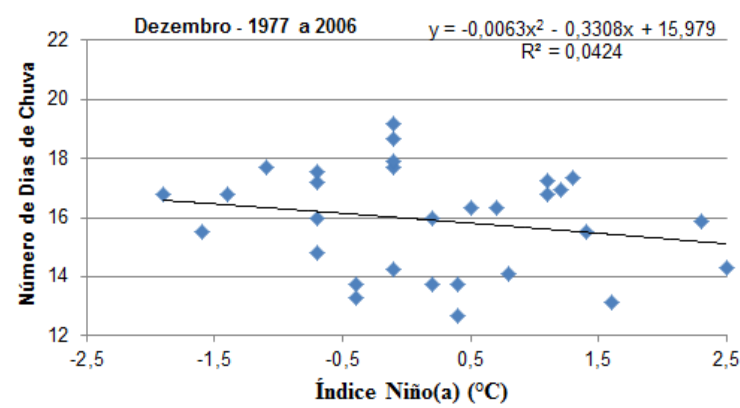

Figura 16 - Dispersão em dezembro do Número de Dias de Chuva em relação ao Índice Niño(a) do período.

No período de 1977 a 2006 (Figura 4) o Índice $\mathrm{Niño(a)} \mathrm{mensal}$ médio variou entre $-1,1^{\circ} \mathrm{C}$ e $1,3^{\circ} \mathrm{C}$, variações consideradas moderadas. $\mathrm{Na}$ Figura 17 o NDC do gráfico se caracteriza com a soma dos dias em que se registrou chuva de cada ano da série histórica. Observa-se que no geral o NDC de cada ano do período não tem uma relação direta com os fenômenos El Niño e La Niña, já que a linha de tendência polinomial de segunda ordem pouco variou. $\mathrm{O}$ maior Índice $\mathrm{Niño}$ médio teve intensidade de $1,3^{\circ} \mathrm{C}$ e foi registrado no ano de 1987 e 1997 nos quais o NDC foi de 103 dias e 111 dias, respectivamente. Já o mais forte Índice Niña médio $\left(-1,1^{\circ} \mathrm{C}\right)$ ocorreu em 1999 , ano no qual se registrou 100 dias de chuva. O ano de 1993 foi o com menor NDC do período (89 dias) e registrou um Índice Niño(a) médio de fraca intensidade $\left(0,5^{\circ} \mathrm{C}\right)$. Dos 365 dias do ano de 1989 choveu em 121 dias, o maior NDC do período e estava sob influência de um Índice Niño(a) médio de $-0,6^{\circ} \mathrm{C}$ (intensidade fraca).

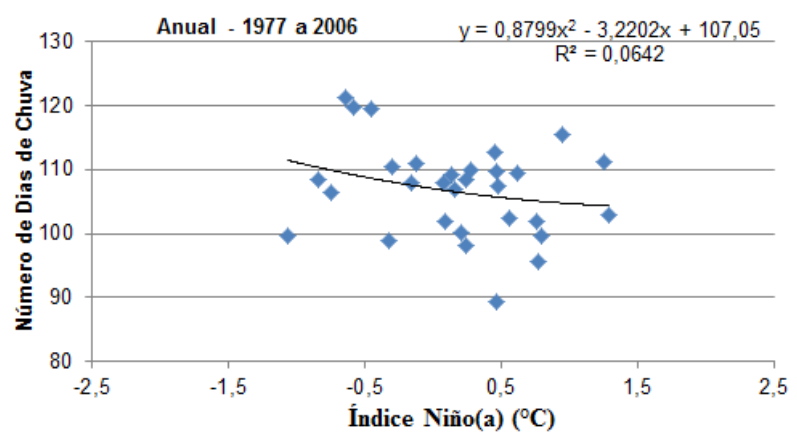

Figura 17 - Dispersão do Número de Dias de Chuva em relação ao Índice Niño(a) do período.

Algumas variações de temperatura do Oceano Pacífico consideradas fortes foram observadas nos anos de $1982\left(2,3^{\circ} \mathrm{C}\right), 1983\left(2,3^{\circ} \mathrm{C}\right)$. $1988\left(-1,9^{\circ} \mathrm{C}\right), 1991\left(1,6^{\circ} \mathrm{C}\right), 1992\left(1,8^{\circ} \mathrm{C}\right)$, $1997\left(2,5^{\circ} \mathrm{C}\right), 1998\left(2,3^{\circ} \mathrm{C}\right), 1999 / 2000$ ($\left.1,6^{\circ} \mathrm{C}\right)$ e $2002\left(1,5^{\circ} \mathrm{C}\right)$. De acordo com a Figura 18 dentro do período estudado (1977-2006) o El Niño aconteceu com maior intensidade no ano de 1997 (variação de $2,5^{\circ} \mathrm{C}$ na temperatura) e a La Niña ocorreu com maior intensidade no ano 1988 (variação de $-1,9^{\circ} \mathrm{C}$ na temperatura). Além disso, no período em estudo houve mais variações positivas de temperatura do que negativas das águas do Oceano Pacífico, caracterizando uma maior frequência do fenômeno El Niño,

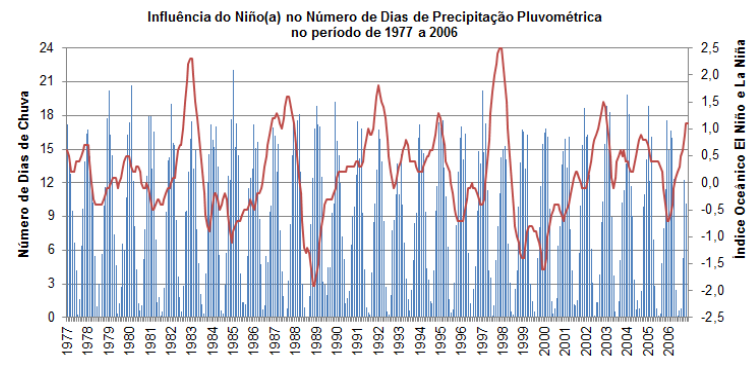

Figura 18 - Influência do Índice Niño(a) no

Número de Dias de Precipitação

Pluviométrica do período. 
$\mathrm{Na}$ análise estatística (Tabela 1) verifica-se que o maior NDC do Estado do Mato Grosso foi obtido no mês de janeiro (aproximadamente 22 dias de chuva) de 1985, quando o Índice Niño(a) estava em $-0,9^{\circ} \mathrm{C}$ (Figura 5). A tendência central (média), que é o centro de um grupo de números em uma distribuição estatística, para os valores de dias de chuva, mostrou uma maior proximidade com os valores máximos nos meses chuvosos (outubro a abril) em relação aos meses secos, que tiveram maior proximidade com os valores mínimos. Marcuzzo et al. (2012) relatam que apenas o mês de março apresenta um aumento no NDC no Mato Grosso, ficando os outros meses do ano e a média geral anual com tendência de decréscimo no NDC.

Em todos os meses, verifica-se que a mediana ficou muito próxima da média. A medida do grau de dispersão dos valores em relação ao seu valor médio mostra que, em média, nos meses de maiores dias de chuva o desvio padrão foi menor que nos meses com menores valores. $\mathrm{O}$ maior desvio padrão foi obtido no mês no mês de abril $(2,2)$, considerado mês úmido, e o menor desvio padrão $(0,7)$ foi obtido no mês de julho, considerado mês seco.

Tabela 1 - Analise estatística do Número de Dias de Chuva do Estado de

\begin{tabular}{crrrrr}
\multicolumn{5}{c}{ Mato Grosso (1977 a 2006). } \\
\hline Meses & Máx. & Méd. & Med. & Mín. & Des. Padrão \\
\hline Jan & 22,1 & 17,2 & 17,1 & 11,0 & 2,0 \\
Fev & 20,7 & 15,3 & 15,0 & 12,2 & 1,8 \\
Mar & 18,3 & 15,0 & 15,6 & 10,1 & 2,1 \\
Abr & 14,5 & 9,3 & 8,9 & 6,2 & 2,2 \\
Mai & 6,6 & 4,0 & 4,0 & 1,4 & 1,3 \\
Jun & 4,2 & 1,4 & 1,2 & 0,2 & 1,0
\end{tabular}

\begin{tabular}{crrrrr} 
Jul & 3,0 & 0,8 & 0,6 & 0,1 & 0,7 \\
Ago & 5,4 & 1,6 & 1,3 & 0,0 & 1,3 \\
Set & 9,4 & 5,0 & 5,1 & 1,9 & 1,6 \\
Out & 12,7 & 9,3 & 9,4 & 6,1 & 1,4 \\
Nov & 15,3 & 12,1 & 11,7 & 9,3 & 1,7 \\
Dez & 19,2 & 15,9 & 16,2 & 12,7 & 1,8 \\
\hline Anual & 121,3 & 106,8 & 108,0 & 89,4 & 7,3 \\
\hline
\end{tabular}

\section{CONCLUSÕES}

Os meses de maio, junho, julho e agosto (final de outono e começo de inverno no hemisfério sul) apresentaram decréscimo ou acréscimo do NDC conforme a intensidade dos fenômenos Niño(a) em estudo, mas sem valores de diferenças significativos. Assim pode-se constatar que nos demais meses do período de 1977 a 2006 os fenômenos El Niño e La Niña pouco interferiram no NDC para o Estado de Mato Grosso. Além disso, a maior parte dos NDC extremos, de cada mês da série histórica, ou seja, aqueles valores que estavam acima ou abaixo da média não ficaram explicitamente caracterizados como associados ao fenômeno ENOS.

Outro fator culminante, para atestar que os fenômenos El Niño e La Niña pouco causam efeitos evidentes no NDC do Estado de Mato Grosso, é o fato de que nos meses de maiores intensidades desses fenômenos as curvas de tendência conservaram-se praticamente estáveis, ou seja, não houve tendência de acréscimo ou decréscimo do NDC dentro do período em estudo. 


\section{REFERÊNCIAS}

BRASIL. Congresso Senado Federal. Comissão El Niño. Relatório Final. Relator Waldeck Ornelas. Brasília: Senado Federal/ Secretaria Especial de Editoração e Publicações, p.192, 1997. EMBRAPA. Empresa Brasileira de Pesquisa Agropecuária. Brasil em Relevo. Disponível em: $<$ http://www.relevobr.cnpm.embrapa.br download/index.htm>. Acesso em: 02/2012.

FISCHER, G. R.; DINIZ, G. B.; MARQUES, J. R. Q. Previsão do número de dias de chuva para a metade sul do Rio Grande do Sul utilizando a Temperatura da Superfície do Mar (TSM). Revista Brasileira Meteorologia, São José Dos Campos, v. 23, n. 2, p.146151, 2008. Disponível em: $<$ http://dx.doi.org/10.1590/S010277862008000200003>. Acesso em: 02/ 2012.

GRIMM, A.M.; FERRAZ, S.E.T.; GOMES, J. Precipitation anomalies in Southern Brazil associated with El Niño and La Niña events. Journal of Climate, v. 11, p.2863-2880, 1998.

GRIMM, A.M.; BARROS, V.R.; DOYLE, M.E. Climate variability in Southern South America associated with El Niño and La Niña events. Journal of Climate, v.13, p.35-58, 2000.

INSTITUTO BRASILEIRO DE GEOGRAFIA E ESTATÍSTICA - IBGE. Censo 2010. Disponível em: $<$ http://www.ibge.gov.br/cidadesat/link. php?uf=to $>$. Acesso em: 06/2012. MARCUZZO, F. F. N. ; OLIVEIRA, N. de L. Impacto do El Niño e La Niña na precipitação máxima diária do estado do Mato Grosso do Sul. Acta

Geografica, v. 6, p. 193-206, 2012.

Disponível em:

$<$ http://revista.ufrr.br/index.php/actageo Larticle/view/630/913>.

MARCUZZO, F. F. N.; OLIVEIRA, N. de L.; CARDOSO, M.R.D. Tendência do Número de Dias de Chuva no Estado do Mato Grosso e a Relação dos seus Extremos com o Fenômeno ENOS. Ciência e Natura, v. 34, p. 59-82, 2012. Disponível em: $<$ http://cascavel.ufsm.br/revista ccne/ojs index.php/cienciaenatura/article/view/7 98/550>.

MORAES NETO, J. M. de; BARBOSA, M. P. e ARAUJO, A. E. de. Efeito dos eventos ENOS e das TSM na variação pluviométrica do semi-árido paraibano. Revista Brasileira de Engenharia. Agrícola e Ambiental, Campina Grande, v. 11, n.1, pp. 61-66, 2007. Disponível em:

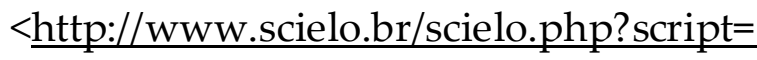
sci arttext\&pid=S1415$\underline{4662007000100008 \& \ln g=e n \& n r m=i s o>}$ Acesso em: 02/2012 NAGHETTINI, M.; PINTO, É. J. A.; 2007. Hidrologia Estatística. Belo Horizonte: CPRM.

NOAA - National Weather Service. 2011. "Monthly Atmospheric \& SST Indices". Disponível em $<$ http://www.cpc.ncep.noaa.gov/data/in dices/> Acesso 02/2012. PEEL, M.C; FINLAYSON, B.L. \& MCMAHON, T.A., 2007. Updated world map of the Köppen-Geiger climate classification, Hydrol. Earth Syst. 
PHILANDER, S.G. e FEDEROV, A. El

Niño é esporádico ou cíclico? Revisão

anual da Terra e Ciências Planetárias,

v.31, p.579-594, 2003.

RIBEIRO, A. M.; LUNARDI, D. M. C. A

precipitação mensal provável para

Londrina - PR, através da função gama.

Revista Energia na Agricultura,

Botucatu, v.12, n.4, p.37-44, 1997. 